\title{
Dissemination of Stock Recommendations and Small Investors: Who Benefits?
}

\author{
Bilgehan Yazici \\ ABN-AMRO Asset Management Turkey Istanbul, Turkey \\ Gülnur Muradoğlu \\ Cass University Business School City of London, UK
}

\begin{abstract}
The objective of this study is to examine whether published investment advice generates higher returns for investors. We investigate the impact of security recommendations in the financial press on common stock prices in Istanbul Stock Exchange. Recommendations of Investor Ali column of the weekly-published popular economics journal Moneymatik constitutes our sample. The column is designed to inform individual investors about company prospects and use them as the basis for its recommendations. The results show that the published investment advice in this column does not help small investors earn excess returns. On the contrary, it provides a valuable deal to its 'preferred investors', if any, in selecting the stocks. If one could front-run the column's recommendations by five days he/she could earn more than $5 \%$ per week in excess of the index return. Compounded annually the excess return of a preferred investor could earn would be more than an amazing $1500 \%$ per annum (JEL G11, G12, G14, G15).
\end{abstract}

Keywords: excess returns, insider trading, investment advice, ISE, stocks.

\section{Introduction}

Small investors utilize investment advice. Low cost financial publications in press, brokerage house recommendations and recently, the web sites that give totally free information and analysis are just a

\footnotetext{
${ }^{*}$ We would like to acknowledge the helpful comments of David Lovette, Meral Varis, Burak Kurt, Hasan Ersel, Tansu Yildirim and Chris Papathanasiou and participants of the $8^{\text {th }}$ Multinational Finance Society Meeting in Italy. We would like to thank Rafet Bilgen and HC Istanbul Securities for kindly supplying the stock price data used in this study.
}

(Multinational Finance Journal, 2002, vol. 6, no. 1, pp. 29-42)

(C) Multinational Finance Society, a nonprofit corporation. All rights reserved.

DOI: $10.17578 / 6-1-2$ 
few examples of investment advice available to small investors. We examined whether published investment advice generates higher returns for small investors by investigating the impact of security recommendations in the financial press on common stock prices at Istanbul Stock Exchange. Istanbul stock Exchange is established in 1986 and is the $8^{\text {th }}$ largest exchange in Europe. Today more than 250 shares are traded in two sessions on a daily basis. The daily volume of trade is about $\$ 800$ million and market capitalisation is about $\$ 13$ billion as of the year 2000.

Recommendations of Investor Ali column of the weekly-published popular economics journal Moneymatik (Paramatik in Turkish) constitutes our sample. The name of the journal makes associations with automatic and ATM machines, and implies that the journal is for those who want manage their investments profitably. Ali is very a common and widely held name in Turkey and the title of the column (Investor Ali) implies that the column is designed for the man on the street, i.e. the small investor. As one of the most widely read features of the Moneymatik, the column has been published weekly since the periodical was introduced in 1993. The coverage of the column includes analysis of macroeconomic conditions as well as the analysis of a single firm or a group of firms. The column is designed to attract individual investors with its informal language and overconfident attitude in the analysis of firm specific information.

Small investors utilise information throughout their decision-making processes from various sources but mainly from the financial media and web-based brokerage house recommendations (Muradoglu [2000]). Web-based, free of charge recommendations can be reached by those who have access to and who are skilled in using computers. Brokerage houses and investment banks usually distribute financial analysts' research reports to larger clients without charge in the expectation that brokerage commissions will be generated. Reading the comments in popular economic periodicals is a low cost way of gathering information for most individual investors. These magazines claim that they provide the widest dissemination of information.

Investment advice that individual investors utilize might also be a basis for insider-trading if the column is well known. Advice can, then, generate trading volume, which insiders can exploit. "Heard on the Street" column of the daily Wall Street Journal had been involved in an insider trading scandal, which was revealed on March 29, 1984. It was uncovered that an author of the "Heard on the Street" column leaked 
information about the content and the timing of the forthcoming column to some stockbrokers and then shared the illegal gains with them. Afterwards, the Securities and Exchange Commission filed criminal charges against the author and brokers. They were finally convicted of fraud and conspiracy for illegally profiting from market sensitive information.

Several authors presented evidence that there is significant abnormal stock price performance on the day of publication of "Heard on the Street" column (Lloyds Davies and Canes, [1978]). They interpreted this result to suggest that analysts provide information to their clients and that the secondary dissemination of analysts' recommendations in the "Heard on the Street" column has an effect on stock prices. Their findings have received support from more recent studies by Liu, Smith and Syed (1990) and Beneish (1991). However, both of these latter papers also found a significant price impact during the two days preceding the publication. Beneish (1991) investigated alternative explanations for the significant stock price reaction to analysts' information reported in "Heard on the Street" column and indicated that the column was not usually a secondary dissemination. Beneish's (1991) evidence suggests that "Heard on the Street" gathers information, forms a consensus, and provides it to investors.

In the Istanbul Stock Exchange, Kiymaz (1999) investigated the effect of stock market gossip published in weekly economics magazine Ekonomik Trend between July 1996 and August 1997. He concluded that statistically significant abnormal returns in the pre-publication period existed and this would possibly be a sign of the profitable use of insider information by those who posses the information initially. Kiymaz (1999) has worked with a limited sample and the column he investigated was presented as dissemination of several analysts' recommendations.

So far, neither the Investor Ali case that we present in this paper, nor the Ekonomik Trend case has been punished for insider trading. There is a grey area whereby it is extremely difficult to distinguish between privileged customers and insiders. In Europe insider trading is mainly understood as illegal trading based on the privileged information held by major shareholders or managers. Issues in the grey area where small investors are involved do not attract much attention. A former British stockbroker in London kindly informed us that practice to the one we 
report in this paper is pretty common in London. ${ }^{1}$ He explained that analysts might have privileged clients with whom they share their recommendations before written material is produced and disseminated. Therefore, we would like to be as sceptic as one can be in discussing the results of this study.

We simply examine the security market reaction to the publication of investment advice in a periodical in the case of Istanbul Stock Exchange. The distinct characteristics of the Turkish case will be explained in detail in the following sections. We only investigate if published investment advice is helpful to small investors in generating excess returns. In doing so, we investigate excess returns for possible front-runners and long-term investors as robustness checks. The remainder of the paper is organized as follows. Section II discusses the data and methodology, section III presents the findings and discussion, and section IV concludes the paper.

\section{Data and Methodology}

Our sample consists of 206 stock recommendations by Investor Ali during the period December 5, 1993 - December 28, 1998. We could not obtain 24 issues of Moneymatik within this period. In addition, in 35 issues Investor Ali either advised sectors instead of specific stocks or recommended staying long in stocks or did not give an advice because of high uncertainty induced by political and economic crisis. When Investor Ali recommends more than one stock in his column, only the major recommendation is picked for that week, i.e. the stock for which detailed background and analysis is given. During the sample period of time, Investor Ali made a total of 206 recommendations and tipped 89 different stocks. Our sample consists of buy recommendations only because Investor Ali has never advised to sell a stock.

The price series of the stocks recommended by Investor Ali were taken from the database at HC Istanbul Securities Research Department. They are adjusted for stock splits and dividends. The event date $(t=0)$ is taken as the first business day after the periodical is published on Sunday. Hence, for each sample observation, the calendar time is converted to event time. Price reactions were measured in a 40 day event window, $(t=-19, \ldots 0, \ldots+20)$.

1. Name to be kept confidential. 
Following Werner and Brown (1984), the abnormal return on stock $i$ on day $t, A R_{i, t}$ is defined as the difference between the return on stock $i\left(R_{i, t}\right)$ and the return on the market $\left(M_{t}\right)$.

$$
A R_{i, t}=R_{i, t}-M_{t}
$$

where ISE-100 composite index represents the market $\left(M_{t}\right)$ and stock returns are defined as the close to close percentage change in the price levels. The average abnormal returns on $n$ stocks at day $t, A R_{t}$ is given as:

$$
A R_{t}=\frac{1}{n} \sum_{i=1}^{n} A R_{i, t}
$$

For $n$ securities, average cumulative abnormal returns $T$ days after the event date, $A C A R_{T}$ is the sum of average abnormal returns over that period:

$$
A C A R_{T}=\sum_{t=0}^{T} A R_{t}
$$

The $t$-statistics for $A C A R_{T}$ is computed as:

$$
t=\frac{A R_{t}}{\sigma / \sqrt{t}}
$$

In this study, we considered an event window that starts on day $t=-19$ and ends on $t=20$ and the $t$-tests are carried out for this event window. The longer event window adopted here enables us to observe the possible existence of persistent abnormal returns after the event as well as price recovery before the event.

\section{Results}

The results indicate that the publication of the Investor Ali column has a significant impact on stock prices. Results presented in table 1 and figure 1 show that the average Cumulative Abnormal Return $(A C A R)$ starts picking up on day $t=-8$. During the period covering $t=-8$ to $t=$ -2 , ACAR increases from $-0.8 \%$ to $0.7 \%$. A clear jump at the $A C A R$ 
TABLE 1. Average Cumulative Abnormal Returns $(A C A R)$ in $t=-19, t=+20$ Event Window

\begin{tabular}{|c|c|c|c|}
\hline & $A C A R$ & $A R$ & $t$-value \\
\hline-19 & 0.0007 & 0.0007 & 0.2765 \\
\hline-18 & 0.0023 & 0.0017 & 0.6093 \\
\hline-17 & -0.0017 & -0.0041 & -0.4001 \\
\hline-16 & -0.0013 & 0.0004 & -0.2843 \\
\hline-15 & -0.0042 & -0.0028 & -0.7635 \\
\hline-14 & -0.0054 & -0.0012 & -0.9143 \\
\hline-13 & -0.0050 & 0.0003 & -0.8064 \\
\hline-12 & -0.0064 & -0.0014 & -0.9959 \\
\hline-11 & -0.0061 & 0.0004 & -0.8808 \\
\hline-10 & -0.0024 & 0.0037 & -0.3003 \\
\hline-9 & -0.0040 & -0.0016 & -0.4636 \\
\hline-8 & -0.0080 & -0.0040 & -0.9179 \\
\hline-7 & -0.0062 & 0.0018 & -0.6987 \\
\hline-6 & -0.0050 & 0.0012 & -0.5430 \\
\hline-5 & -0.0005 & 0.0045 & -0.0502 \\
\hline-4 & 0.0014 & 0.0019 & 0.1313 \\
\hline-3 & 0.0048 & 0.0035 & 0.4417 \\
\hline-2 & -0.0073 & 0.0025 & 0.6806 \\
\hline-1 & 0.0303 & 0.0230 & 2.7460 \\
\hline 0 & 0.0539 & 0.0235 & 4.3018 \\
\hline 1 & 0.0541 & 0.0002 & 4.2699 \\
\hline 2 & 0.0523 & -0.0018 & 4.1809 \\
\hline 3 & 0.0488 & -0.0035 & 3.8815 \\
\hline 4 & 0.0535 & 0.0047 & 4.1992 \\
\hline 5 & 0.0515 & -0.0020 & 3.8583 \\
\hline 6 & 0.0502 & -0.0013 & 3.6843 \\
\hline 7 & 0.0458 & -0.0044 & 3.3913 \\
\hline 8 & 0.0444 & -0.0014 & 3.3481 \\
\hline 9 & 0.0410 & -0.0034 & 3.1346 \\
\hline 10 & 0.0412 & 0.0001 & 3.1408 \\
\hline 11 & 0.0386 & -0.0026 & 2.9641 \\
\hline 12 & 0.0345 & -0.0040 & 2.6308 \\
\hline 13 & 0.0323 & -0.0022 & 2.3981 \\
\hline 14 & 0.0355 & 0.0031 & 2.5568 \\
\hline 15 & 0.0310 & -0.0045 & 2.1749 \\
\hline 16 & 0.0278 & -0.0031 & 1.9686 \\
\hline 17 & 0.0238 & -0.0040 & 1.6657 \\
\hline 18 & 0.0235 & -0.0003 & 1.6107 \\
\hline 19 & 0.0021 & -0.0013 & 1.4986 \\
\hline 20 & 0.0204 & -0.0017 & 1.3666 \\
\hline
\end{tabular}

Note: This table reports the $A C A R \mathrm{~s}$ and $A R \mathrm{~s}$ for the full sample for the event window $t$ $=-20$, to $t=+20$. The Cumulative abnormal returns $(A C A R)$ and daily abnormal returns $(A R)$ are calculated as described in equations 3 and 2 respectively in the text with related test statistics given in equation 4. Test statistic follows a Student's $t$-distribution under the null hypothesis. The $t$-statistics reported in the table refer to the test statistics for ACAR only. 
Figure 1: A verage Cum ulative Abnormal Return I (ACAR) I the ihortrun. (t=-19, $t=20$ )

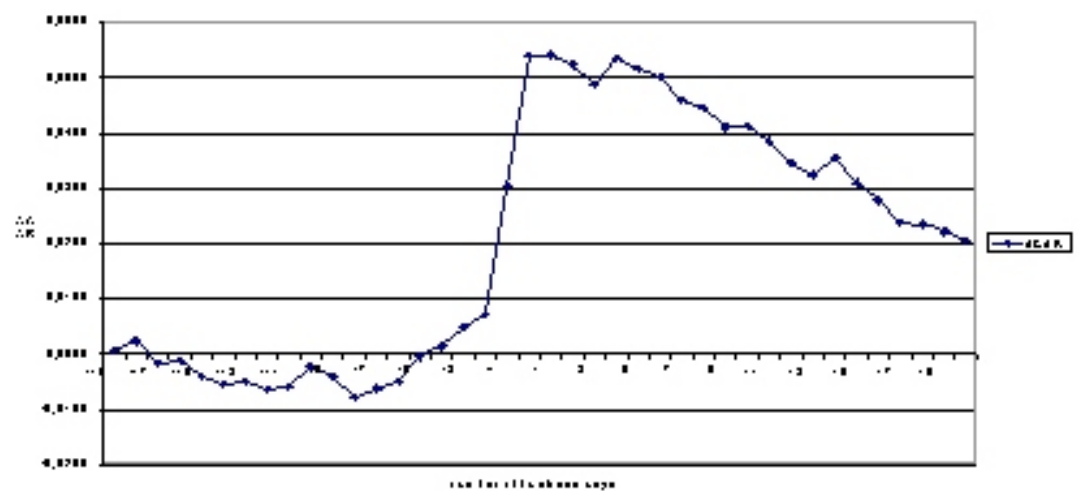

from $0.7 \%$ to $3.0 \%$ can be observed at the one business day before Investor Ali advises the stock on Sunday. After the advice appears in Moneymatik on Sunday, $(t=0)$ another significant jump to $5.39 \%$ can be observed.

On the event date, which is the first Monday after investment advice is published, the abnormal returns are approximately $2.35 \%$. After the event date $(t=+1)$, the $A C A R$ is almost constant at $5.4 \%$ and then decays gradually to $2.0 \%$ on day $t=+20$. So, between $t=+1$ and $t=$ +20 , we observe negative $A C A R$ of $-3.4 \%$.

We examine the $A C A R$ s during the one-week before and after the publication of the Investor Ali column $(t=-5$ to $t=+5)$. Table 2 and figure 2 report results for the ten day event window. We observe that cumulative abnormal returns increase from zero $(t=5)$ to $3.0 \%(t=-1)$ in one week until the Friday just before the publication of the Journal on Sunday. On the Monday, which is the first trading day following the publication of investment advice $A C A R$ jumps to $5.39 \%(t=0)$ and remain constant during the rest of the week. On the Friday following the publication of the column $A C A R$ is stable at $5.35 \%(t=+5)$.

Despite the poor performance in the short run investment advice might be valuable in the long run. The forty day event window we use in table 1 is far too short to evaluate the long term value of the columnist's advice. It is argued that equity investments must be held over a long period to realise their full value. ${ }^{2}$ We investigate long run returns during a two year period. We report the weekly cumulative

2. We would like to thank a anonymous referee for suggesting the analysis of long-term value of investment advice. 
TABLE 2. Average Cumulative Abnormal Returns $(A C A R)$ in $t=-5, t=+5$ Event Window

\begin{tabular}{lccc}
\hline & $A C A R$ & $A R$ & $t$-value \\
\hline-5 & 0.0045 & 0.0045 & 0.4370 \\
-4 & 0.0064 & 0.0019 & 0.5815 \\
-3 & 0.0099 & 0.0035 & 0.9204 \\
-2 & 0.0123 & 0.0025 & 1.1157 \\
-1 & 0.0354 & 0.0230 & 2.8245 \\
0 & 0.0589 & 0.0235 & 4.6501 \\
1 & 0.0591 & 0.0002 & 4.7281 \\
2 & 0.0573 & -0.0018 & 4.5598 \\
3 & 0.0538 & -0.0035 & 4.2249 \\
4 & 0.0585 & 0.0047 & 4.3838 \\
5 & 0.0565 & -0.0020 & 4.1465 \\
\hline
\end{tabular}

Note: This table reports the $A C A R \mathrm{~s}$ and $A R \mathrm{~s}$ for the full sample for the event window $t$ $=-5$, to $t=+5$. The Cumulative abnormal returns $(A C A R)$ and daily abnormal returns $(A R)$ are calculated as described in equations 3 and 2 respectively in the text with related test statistics given in equation 4. Test statistic follows a Student's $t$-distribution under the null hypothesis. The $t$-statistics reported in the table refer to the test statistics for ACAR only.

Figure 2 : A verage Cum ulative Abnorm al Return I (ACAR) In the ilnortrun. (t=-5, $t=+5$ )

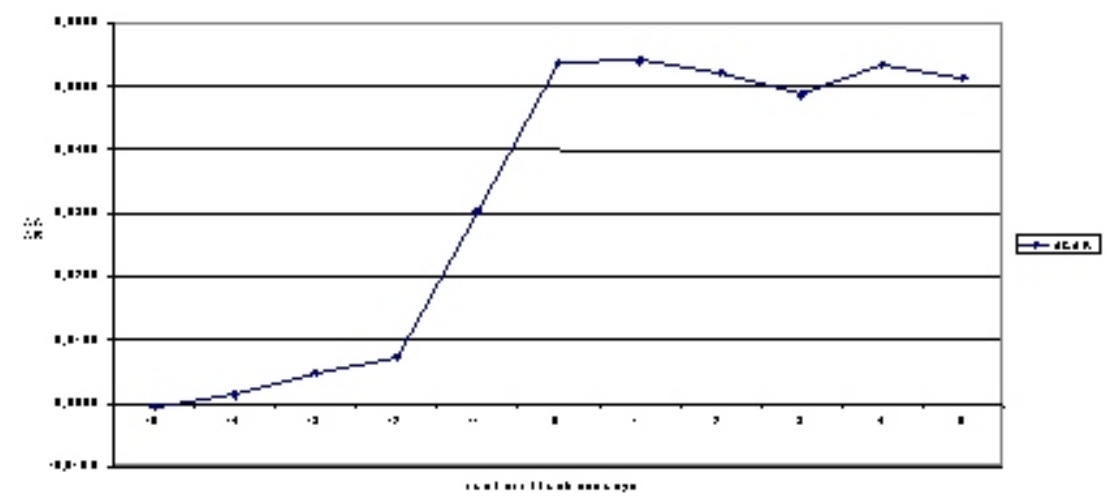

abnormal returns for two years until week 104, following the recommendations of the Investor Ali column in table 3 and figure 3.

$A C A R$ s are negative throughout the two year period following the columnist's advice. ACARs systematically decline from zero to $-8.4 \%$ in six months (week $=26$ ) and to $10.0 \%$ (week=52) at the end of the first year. The decline continues during the second year and $A C A R$ is $-13.6 \%$ 
TABLE 3. Average Cumulative Abnormal Returns ( $A C A R)$ in the Long Run. One Year $(t=0, t=+260)$ and Two Years $(t=0, t=+520)$ Event Window.

\begin{tabular}{lrrr}
\hline & $A C A R$ & $A R$ & $t$-value \\
\hline 0 & -0.0007 & -0.0007 & -0.0006 \\
25 & -0.0438 & -0.0056 & -0.0148 \\
50 & -0.0622 & -0.0021 & -0.0141 \\
75 & -0.0897 & -0.0032 & -0.0172 \\
100 & -0.0861 & 0.0002 & -0.0148 \\
125 & -0.0804 & -0.0015 & -0.0131 \\
150 & -0.0972 & -0.0046 & -0.0140 \\
175 & -0.1311 & -0.0112 & -0.0177 \\
200 & -0.1130 & -0.0041 & -0.0139 \\
225 & -0.0910 & 0.0006 & -0.0114 \\
250 & -0.0951 & 0.0052 & -0.0112 \\
260 & -0.1057 & 0.0000 & -0.0124 \\
275 & -0.0980 & 0.0062 & -0.0117 \\
300 & -0.0970 & 0.0034 & -0.0108 \\
325 & -0.1001 & -0.0021 & -0.0101 \\
350 & -0.1088 & 0.0062 & -0.0105 \\
375 & -0.1189 & -0.0101 & -0.0116 \\
400 & -0.1391 & 0.0053 & -0.0132 \\
425 & -0.1012 & 0.0045 & -0.0099 \\
450 & -0.1040 & -0.0080 & -0.0098 \\
475 & -0.1195 & -0.0108 & -0.0108 \\
500 & -0.1309 & 0.0028 & -0.0111 \\
520 & -0.1394 & -0.0031 & -0.0114 \\
\hline
\end{tabular}

Note: This table reports the $A C A R \mathrm{~s}$ and $A R \mathrm{~s}$ for the full sample for the event window $t$ $=0$, to $t=+520$. The Cumulative abnormal returns $(A C A R)$ and daily abnormal returns $(A R)$ are calculated as described in equations 3 and 2 respectively in the text with related test statistics given in equation 4. Test statistic follows a Student's $t$-distribution under the null hypothesis. The $t$-statistics reported in the table refer to the test statistics for $A C A R$ only.

igure 3: Average Cumulative Abnormal Returns (ACA $R$ ] for one year. $[t=0, t+260$ ]

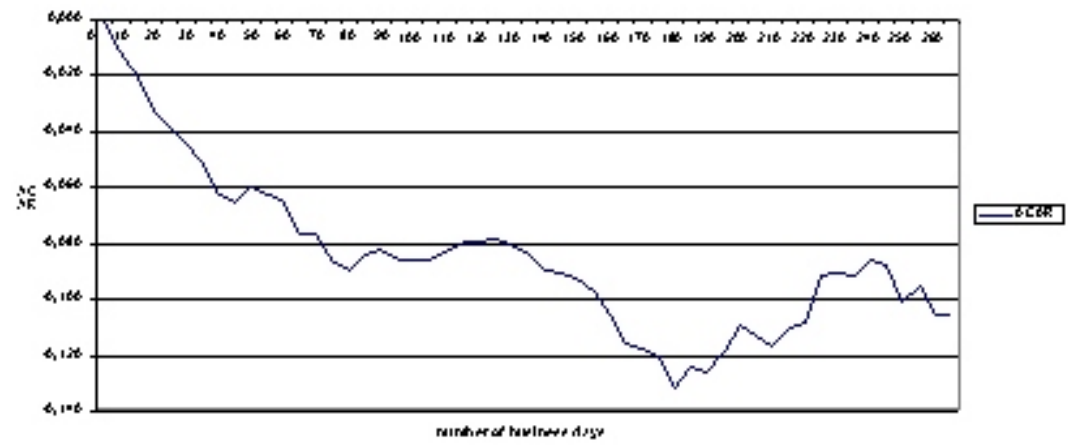


(week=78) eighteen months after the publication of advice, and remain stable at $-13.9 \%$ (week=104) until the end of the second year following the recommendation of the columnist. Clearly the Investor Ali column is not adding any long term value to small investors.

Lloyds-Davies and Canes (1978) interpret similar abnormal price movements in the U.S. by suggesting that the "Heard on the Street" column is a secondary dissemination of analysts' recommendations. However, this can hardly be the explanation for our case. Investor Ali claims that his recommendations are based on his own analyses and do not refer to any financial analyst or street gossip. He often feels the need to state this to differentiate himself from similar columns in other popular economic periodicals. Similar to Liu, Smith and Syed (1990), Beneish (1991) and Kiymaz (1999), we too cannot exclude the possibility of the insider trading during the short time period between Investor Ali's recommendations being submitted to the periodical and the publication of the column. However we are not in a position to make such a claim either.

The significant abnormal returns preceding the publication of the column might very well be due to chance or due to trading based upon speculation or knowledge about the contents of the forthcoming Investor Ali column. One possible story can be the trading of 'preferred investors' who reach the information before the publication day. After investment advice is published, there is a tremendous demand on the first trading day by individual investors, which moves $A C A R$ by almost $2.4 \%$. After the event date, 'preferred investors' might have started selling the stocks that they have already accumulated in the preceding week and exploit the excess returns. If investment advice were given to the magazine on Monday $(t=-5)$ and if this information were tipped to 'preferred investors', they could have bought the stocks five trading days before the publication of the advice. They could have easily sold their stocks after the investment advice had become public information at $(t=0)$. Therefore, they could have earned a weekly average return of $7.11 \%$ and weekly average abnormal return of $5.36 \%$ (see table 2 ) that would easily cover two-way transaction costs of $0.5 \%$ on market average. This corresponds to the remarkable annually compounded return of $1511 \%$.

We run an investment strategy for the front-runners by buying at $(t$ $=-5)$ and selling at $(t=0)$ for the 206-week research period. We find 


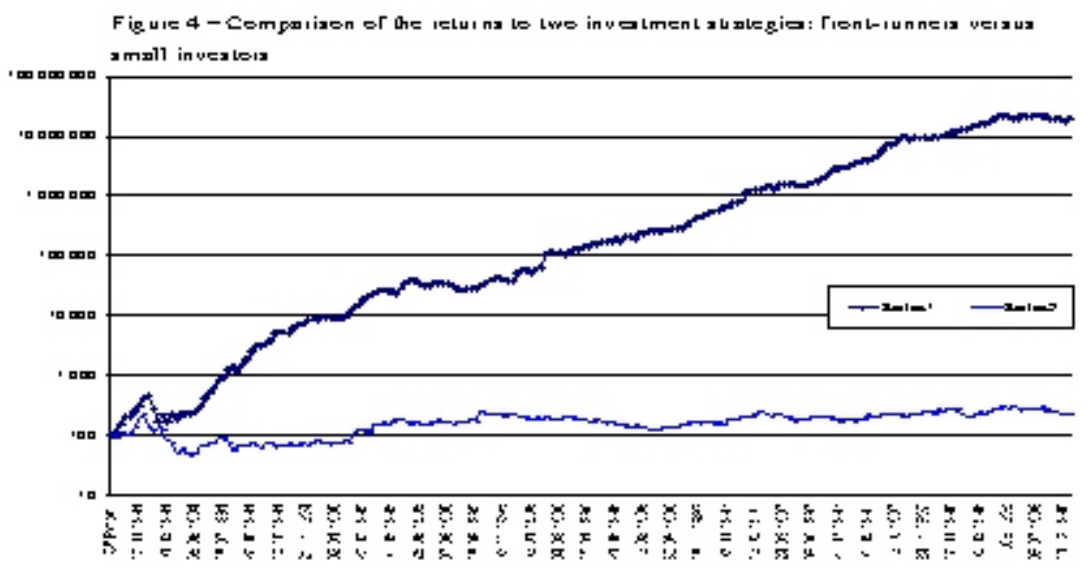

FIGURE 4.- Series 1 represents the long term returns to the strategy for preferred investors/front runners; buy when $(t=-5)$ and sell when $(t=0)$. Series 2 represents the long term returns to the strategy for small investors; buy when $(t=0)$ and sell when $(t=+4)$

that an investment of $\mathrm{TL}^{3} 100$ at the beginning of the period they would end up as TL 19,406,827 (and TL 6,945,221 if transaction costs subtracted) in 5 years. (series 1 in figure 4 ). But as we mentioned before this profitable strategy is merely for 'preferred investors' who might have advance information on the next week's favourite stock in Investor Ali column of Moneymatik. For the same period of time if an ordinary investor invested TL 100 to the index and employed the same investment strategy to ISE100 index, i.e. buy when $(t=-5)$ and sell when $(t=0)$, he/she could only obtain TL 1,516. Alternatively, if the investor had TL 100 worth of US dollars, the equivalent would be TL 1,794 at the end of the period.

Individual investors can have the information only after it has been published. So, they do not have a chance to buy the stock before $(t=0)$. In this case, we can only run an investment strategy to buy at $(t=0)$ when the $A C A R$ is $5.39 \%$ and sell at $(t=+4)$ when $A C A R$ is $5.35 \%$ (see table 1). The investors' abnormal return for a week is $-0.04 \%$. At the end of the 206-week period of time the individual investor's TL 100 reaches to only TL 222 (series 2 in figure 4), and just TL 80 if transaction costs are subtracted. However, for the same period, with the

3. Turkish Lira. 
same strategy individual investor could reach TL 566 by investing in index. There is no excess return but a huge loss relative to the index return for individual investors following the Investor Ali column.

\section{Discussions and Conclusions}

The findings of this paper reveal that buy recommendations published in the Investor Ali column of the journal Moneymatik are associated with positive and significant abnormal returns on the day of publication of Moneymatik and the preceding days. The average abnormal return for the event date is $2.35 \%$ and the cumulative abnormal returns over the one-week period from the 5 days before the publication to the publication day ( $t=-5$ to 0 ) is $5.39 \%$. The abnormal return over the one-week period after the publication date is $-0.04 \%$.

Studies investigating the effect of investment advice in popular press has triggered some criminal inspections in United States. A collusive agreement between "Heard on the Street" reporter Winans and broker Brant led in April 1984 to a Securities and Exchange Commission (SEC) investigation and trial for misappropriation of information. The Judge defined the crime as "During 1983 and 1984, defendants made pre-publication trades on the basis of their advance knowledge of approximately twenty-seven Wall Street Journal 'Heard' columns, although not all of these column were written by Winans. Generally, Winans would inform Brant of the subject of an article the day before its scheduled publication. Winans usually made his calls to Brant from a pay phone, and often used a fictitious name. The net profits from the scheme approached \$690.000" The SEC estimated this amount when taking into account trading in all accounts connected with the defendants. The conviction of a US district court on June 1985, was upheld by a US court of appeals on May 1986, and by the Supreme Court on November 1987. The Judge held that "the information allegedly stolen from the Wall Street Journal was the timing, content, and tenor of market sensitive stories scheduled to appear in the paper." He also found that "the column does have an impact on the market difficult though it may be to quantify it in any particular case. It is certainly obvious that the defendants believed the column had such an impact"

The case described above indicates two important points. First stock prices are affected by recommendations and possible abuse of this 
power is a common practise not only in ISE but also in the most advanced stock exchanges of the world. Second this sort of abuse could be diminished through strict and effective regulatory mechanisms, and thus, increasing the efficiency of the markets. In light of the above examples, the question of how to make ISE more efficient and in what ways the existing (or new) legal regulations could be introduced and implemented to achieve such goals are possible areas for new studies. This appears to be an open field for further research. The results in this paper show that the published investment advice in a periodical may not offer a helpful service for the ordinary small investors but provides a valuable deal to its 'preferred investors', if any, in selecting the stocks. We have demonstrated that 'preferred investors' can achieve superior abnormal returns by front-running the column's recommendations, whilst the small investors make a modest return that is far less than the gains they would have made by buying and holding the index.

\section{References}

Beneish, M.D. 1991. Stock prices and the dissemination of analyts' recommendations. Journal of Business 64: pp. 393-416.

Bjerring, J.H.; Lakonishok, J.; and Vermaelen, T. 1983. Stock prices and financial analyts' recommendations. Journal of Finance 38:1 87-204.

Brown, S., and Werner, J. Using daily stock returns: The case of event studies. Journal of Financial Economics 14: 3-31.

Fama, E.F. 1990. Stock returns, expected returns and real activity. Journal of Finance 45: 1089-1108.

Federal Reporter. 1986. United States of America v. David Carpenter, Kenneth P. Felis, and R. Foster Winans. U.S. Court of Appeals 791: 1024-37. St. Paul: West Publishing Co.

Federal Supplement. 1985. United States of America v. R. Foster Winans, David Carpenter, and Kenneth P. Felis. U.S. District Courts 627: 827-50. St. Paul: West Publishing Co.

Kiymaz, H. 1999. The effects of "stock market gossip" on stock prices: The ISE experience. Iktisat, Isletme ve Finans, 164: 20-29.

Lloyds-Davies, P., and Canes, J. 1978. Stock prices and the publication of second hand information. Journal of Business 51: 43-56.

Liu P.; Smith D.S.; and Syed A.A. 1990. Stock price reactions to The Wall Street Journal.

Journal's Securities Recommendations. Journal of Financial and Quantitive Analysis, 25, pp. 399-410

Marton A. 1987. Drawing the line on front-running. Institutional Investor 21: 
$145-148$.

Moneymatik. 5 December 1993 - 12 July 1998

Muradoglu, G. Turkish stock market: Anomalies and profit opportunities in security market imperfections in worldwide equity markets. (Ed. Keim, D. and Ziemba, W.) Cambridge University Press. 2000. p.364-389.

Thompson R.B.; Olsen C.; and Dietrich J.R. 1987. Attributes of news about firms: An analysis of firm-spesific news reported in the Wall Street Journal index. Journal of Accounting Research 25: 245-274. 